\title{
Development and implementation of an instrument to assess privacy challenges of a web-based liver transplantation registry
}

\author{
Khalil Kimiafar $^{1}$, Alireza Banaye Yazdipour ${ }^{1,2}$, Benyamin Hoseini ${ }^{3,4}$, Masoumeh Sarbaz ${ }^{1}$
}

${ }^{1}$ Department of Medical Records and Health Information Technology, School of Paramedical Sciences, Mashhad University of Medical Sciences, Mashhad, Iran

${ }^{2}$ Student Research Committee, Mashhad University of Medical Sciences, Mashhad, Iran

${ }^{3}$ Department of Health Information Technology, Neyshabur University of Medical Sciences, Neyshabur, Iran

${ }^{4}$ Pharmaceutical Research Center, School of Pharmacy, Mashhad University of Medical Sciences, Mashhad, Iran

Type of article: Original

\begin{abstract}
Background: The privacy issue in web-based registry systems is very important and patients are concerned about it. Protecting patients' privacy in medical databases is an important challenge in health informatics.

Objectives: The aim of this study was to develop an instrument to assess privacy challenges of a web-based liver transplantation registry (WLTR), and to determine the views of patients on the privacy of the implemented WLTR.

Methods: This study consisted of two parts: 1) an instrument development phase, in which we developed and implemented an instrument, and 2) a cross-sectional study. The instrument included a total of 59 questions based on literature review. Content validity method was performed to confirm the questionnaire validity and its reliability was evaluated based on the test-retest method. The second phase of the study included all patients who received liver transplantation ( $\mathrm{n}=81$ ) between February 2017 and April 2017 in the only organ transplant center in northeastern and eastern Iran. The data were collected using the instrument that we have developed in the first phase of the study. Data were analyzed by SPSS version 16, using descriptive statistics, Mann-Whitney U test, and Spearman's Rank-Order Correlation test. P-value less than 0.05 was considered statistically significant.

Results: In the first phase, a researcher-made questionnaire consisting of 71 questions was prepared based on the extensive literature review. Necessary modifications were made to match the questionnaire with research topic by Delphi technique (12 questions were removed and 10 questions modified). The final questionnaire included 59 questions about demographic information (age, gender, education level), different dimensions of privacy (24 questions), tendency to trust (9 questions), availability of identifiable and unidentifiable health information for different users (18 question), and the goals of using identifiable and unidentifiable health information (8 questions). Reliability was evaluated based on the test-retest method ( $\mathrm{r}=0.82)$. In the second phase, we determine the views of patients who received liver transplantation on privacy in the WLTR. Most patients (74.1\%) stated that they were worried about privacy risks in online systems. The sensitivity to using online personal health information in women was higher in comparison to men $(\mathrm{p}=0.008)$. Older people have less tendency to use Internet systems to perform activities $(\mathrm{p}=0.023)$. In addition, age had a negative relationship with the convenience of using web-based registry $(\mathrm{p}=0.033$, rho $=-239)$. Regarding the purposes of using the WLTR information from the patients' views, the use of information for purposes of health care had the highest mean, and the use of this information for research purposes had the lowest mean.

Conclusions: Designers and developers of these systems must, in accordance with the objectives of the registry program, and the users of these systems, develop policies for protecting the privacy of patients.
\end{abstract}

Keywords: Privacy, Liver transplantation, Web-based registry, Iran

\section{Corresponding author:}

Masoumeh Sarbaz, Department of Medical Records and Health Information Technology, School of Paramedical Sciences, Mashhad University of Medical Sciences, Mashhad, Iran.

Tel: +9851-38846725, Fax:+9851-38846728, E-mail: sarbazm@mums.ac.ir

Received: June 02, 2018, Accepted: September 17, 2018, Published: March 2019

iThenticate screening: October 11, 2018, English editing: November 12, 2018, Quality control: February 12, 2019

This article has been reviewed / commented by four experts

Funding / research project approval: Mashhad University of Medical Sciences (Grant Number: 951256).

(C) 2019 The Authors. This is an open access article under the terms of the Creative Commons Attribution-NonCommercialNoDerivs License, which permits use and distribution in any medium, provided the original work is properly cited, the use is non-commercial and no modifications or adaptations are made. 


\section{Introduction}

Liver transplantation is regarded as a life-saving treatment for patients with acute liver failure $(1,2)$. The first liver transplantation in Iran was performed in 1993 (3). In recent years, the number of liver transplantations in Asia and Iran has increased rapidly $(4,5)$. Mashhad Organ Transplant Center, the largest transplant center in eastern Iran, implemented in 2001, established a Web-based Liver Transplantation Registry (WLTR) in 2015 (6). The liver transplantation registry is capable of improving the quality of care by providing comprehensive information for caregivers. In the USA, a secure web-based transplantation registry collects comprehensive data from the entire transplantation process from before performing the transplantation up to graft failure or death (7). Web-based registries provide access to real-time data in different places and times, and can easily update and reduce costs $(8$ 12). Data security, especially in electronic data exchange, should be addressed while health care moves towards the digitization of patient medical data $(8,9)$. Privacy is considered an important moral issue in the information age, and people whose data is exchanged electronically should be made aware of the ways in which information is protected (13). All information in the registry must be kept confidential because of the patient identification and clinical data contained within. The majority of patients believe that if their identification information is removed, there is no problem in sharing their sensitive information for medical research (14). Compliance of information confidentiality policies is necessary in all operational stages of registries, and the privacy of not only patients but also physicians and healthcare providers who report cases of the registry should be protected. Generally, guaranteeing data from abuse, and respecting all privacy and data protection rules should be addressed (7).

Patients' viewpoints and their trust in health information systems could affect their participation and adherence to treatment and drug prescriptions. Compliance with treatment and regular referral of patients in follow-up sessions is critical for the improvement of disease and survival of patients after liver transplantation, and privacy challenges can affect this issue as a risk factor $(15,16)$. Recently, studies highlighted the importance of implementing health outcome registries in Mashhad (17-20), however, we found no study that addressed privacy aspects of the registries in Mashhad. Accordingly, the present study aimed to develop an instrument to assess privacy challenges of a webbased liver transplantation registry (WLTR), and to determine the views of patients on the privacy of the implemented WLTR.

\section{Material and Methods}

\subsection{Research design and participants}

This study consisted of two parts: 1) an instrument development phase, in which we developed and implemented an instrument, and 2) a cross-sectional study. The study was conducted from February to April 2017. In the second phase, the study included all patients who received liver transplantation, and their data were recorded in WLTR implemented at a specialized transplant hospital in Mashhad University of Medical Sciences (the only organ transplant center in northeastern and eastern Iran). The inclusion criterion was having a liver transplant (regardless of age or level of education). Those patients unable to take part in the study because of tiredness, or unwillingness due to mental problems were excluded.

\subsection{Instrument development}

First, a researcher-made questionnaire consisting of 71 questions was prepared based on the extensive literature review (21-29). The main sources of item extraction were Richards and Terry et al. studies (21, 22). Necessary modifications were made to match the questionnaire with research topic by Delphi technique (30) using three health informatics and two nephrology experts' opinions (12 questions were removed and 10 questions modified). The final questionnaire included questions about demographic information (age, gender, education level), different dimensions of privacy ( 24 questions), tendency to trust ( 9 questions), availability of identifiable and unidentifiable health information for different users (18 question), and the goals of using identifiable and unidentifiable health information (8 questions). Responses were evaluated in a seven-choice Likert scale (strongly disagree $=1$ to strongly agree $=7$ ).

\subsection{Validity and reliability}

In order to measure the face and content validity of the final questionnaire, five faculty members (three health informatics and two health information management experts) and two patients were consulted on different occasions and asked to score the items on a scale of $0-5$ in terms of the necessity of inclusion. The scores 0 and 5 represented the non-necessity and necessity of inclusion in the questionnaire, respectively. The necessity of the items was divided into three groups: very important (items which received a score of $4-5$ from $75 \%$ of the specialists), average importance (items which received a score of $4-5$ from $50-75 \%$ of the specialists), and not important (data elements 
which received a score of $4-5$ from less than $50 \%$ of the specialists). Items remained in the questionnaire if their necessity of inclusion were very important; otherwise, they were removed. The test-retest method was used to evaluate the questionnaire's repeatability or reliability in repeated administrations. The questionnaire was administered to 10 patients who had liver transplantation in a 2-week interval as a pilot study. Spearman's RankOrder Correlation test was used to examine the questionnaire's repeatability in the test-retest method, with an acceptable result $(\mathrm{r}=0.82)$.

\subsection{Data collection of second phase}

In the second phase of this study, the questionnaire was distributed among patients in hospital and the place where the registration program was carried out on the days of referral for the periodic examination, and they were asked to complete the questionnaires and return them to the researcher within 72 hours.

\subsection{Ethical considerations}

After explaining the purpose of study, confidentiality of data, the voluntary nature of participation and obtaining oral informed consent, the researcher would ask patients to complete the questionnaire. Questionnaire items were read verbatim to those unable to complete the questionnaire. The method of completing the questionnaire was anonymous in order to respect the privacy of participants and ensure the confidentiality of their information, and the study was approved at the Regional Ethics Committee of Mashhad University of Medical Sciences (Ref: IR.MUMS.REC.1395.488).

\subsection{Statistical analysis}

Statistical analysis was performed on this data using SPSS 16.0 (SPSS Inc., Chicago, Illinois, USA). First, normality of the data was assessed by Kolmogorov-Smirnov test, and owing to abnormality of the data Mann-Whitney U test and Kruskal-Wallis tests were used to assess the relationship between participants' views and their gender and level of education, respectively. Spearman's Rank-Order Correlation test was performed to test correlation between age and patients' views on privacy concerns. P-value less than 0.05 was considered statistically significant.

\section{Results}

In the first phase, a researcher-made questionnaire consisting of 71 questions was prepared based on the extensive literature review. Necessary modifications were made to match the questionnaire with research topic by Delphi technique using three medical informatics and two health information management experts' opinions (12 questions were removed and 10 questions modified). The final questionnaire included 59 questions about demographic information (age, gender, education level), different dimensions of privacy ( 24 questions), tendency to trust (9 questions), availability of identifiable and unidentifiable health information for different users (18 question), and the goals of using identifiable and unidentifiable health information (8 questions) (Table 1). Reliability was evaluated based on the test-retest method ( $\mathrm{r}=0.82)$. In the second phase, the questionnaire was distributed to 115 patients, and 81 patients completed the questionnaire (response rate: 70.4\%). The demographic characteristics of patients are shown in Table 2. The majority of participants (54.3\%) were men with mean age of $45.26 \pm 14.39$ years, and the majority (49.4\%) of them had diploma education.

All patients stated that they had not received any statement on the confidentiality of information and privacy, and $95.1 \%$ of them said that they had not been given any verbal explanations in this regard. Most patients (74.1\%) strongly agreed with this sentence: "I am worried about privacy risks in online systems". Table 1 shows that the highest score $(5.81 \pm 1.50)$ was related to the importance of privacy in the online systems and the lowest score (3.77 \pm 1.58$)$ was related to creating unwanted problems when providing personal information to web-based systems. About the patients' attitude towards trust, the majority of patients (mean= 5.80) believed that most professional people do their job in the best way possible. The security of web-based systems for conducting personal business activities (mean $=3.08 \pm 1.65$ ), trust in fulfilling the obligations of Internet services vendors (mean= 3.61 \pm 1.63 ), and the suitability of these companies to serve customers (mean $=3.88 \pm 1.55$ ) obtained the lowest mean. Regarding the purpose of using WLTR and the perceived usefulness of this system, the majority of patients (mean $=5.47 \pm 1.30$ ) believed that the use of WLTR would help health care personnel to perform tasks related to patient health care more quickly. Regarding the role of this system in facilitating the tasks, promoting the quality of care, and effectiveness in performing tasks, the means obtained were $5.37 \pm 1.34,5.45 \pm 1.21$ and $5.42 \pm 1.29$, respectively. Table 1 shows that the majority of patients stated that physicians are permitted to have access to their personal health information including identifiable (mean= 6.21) and unidentified information (mean=6.57) in the WLTR, while the tendency to access identifiable (mean=3.68) and unidentifiable (mean= 5.94) information had the lowest score for employers. 
The purposes of using the registry information, the use of identifiable (mean= 5.75) and unidentified (mean= 6.52) information for the purposes of healthcare had the highest mean, and the use of this identifiable (mean= 4.71) and unidentified (mean= 6.41) information for the research purposes had the lowest mean. Table 3 indicates the values of $p$ (statistical significance) where it was observed that there was a statistically significant relationship between patients' views on privacy concerns and age, level of education, and gender $(\mathrm{p}<0.05)$. Older people had less tendency to use the Internet to perform their activities $(p=0.023)$. In addition, the correlation was performed by Spearman's Rank-Order Correlation test, age had a negative relationship with the convenience of using web-based systems $(r=-239, p=0.033)$.

Table 1. The researcher-made questionnaire designed to assess patients' views on the privacy of the WLTR

\begin{tabular}{|c|c|c|c|c|}
\hline Domain & Sub-domain & Items & Mean \pm SD & $\begin{array}{l}\text { Total Mean } \\
\pm \mathrm{SD}\end{array}$ \\
\hline \multirow[t]{25}{*}{ Privacy Concerns } & \multirow{4}{*}{$\begin{array}{l}\text { Privacy } \\
\text { Concerns }\end{array}$} & I get annoyed when websites get a lot of information from me. & $4.62 \pm 1.63$ & \multirow[t]{4}{*}{$5.23 \pm 1.47$} \\
\hline & & $\begin{array}{l}\text { I am concerned that websites collect high amounts of my } \\
\text { personal information. }\end{array}$ & $5.35 \pm 1.46$ & \\
\hline & & $\begin{array}{l}\text { I am worried that unauthorized persons may access my } \\
\text { personal information. }\end{array}$ & $5.59 \pm 1.29$ & \\
\hline & & I am worried about submitting my information to websites. & $5.37 \pm 1.33$ & \\
\hline & \multirow[t]{3}{*}{ Privacy Intrusion } & $\begin{array}{l}\text { I feel that as a result of using WLTR, others know about me } \\
\text { more than I would like. }\end{array}$ & $3.95 \pm 1.75$ & \multirow[t]{3}{*}{$5.02 \pm 1.70$} \\
\hline & & $\begin{array}{l}\text { I believe that as a result of using these systems, if my } \\
\text { information is used outside the scope of these systems, my } \\
\text { privacy is invaded. }\end{array}$ & $5.62 \pm 1.37$ & \\
\hline & & $\begin{array}{l}\text { I feel that as a result of using these systems, when all my data } \\
\text { are collected by others, my privacy is invaded. }\end{array}$ & $5.49 \pm 1.42$ & \\
\hline & \multirow[t]{4}{*}{ Privacy Risks } & In general, giving personal information to WLTR can be risky. & $3.80 \pm 1.59$ & \multirow[t]{4}{*}{$3.89 \pm 1.60$} \\
\hline & & $\begin{array}{l}\text { There is a relationship between the provision of personal } \\
\text { information to these systems and the loss of privacy. }\end{array}$ & $3.83 \pm 1.56$ & \\
\hline & & $\begin{array}{l}\text { Personal information may be inappropriately used by these } \\
\text { systems. }\end{array}$ & $4.16 \pm 1.65$ & \\
\hline & & $\begin{array}{l}\text { Providing my personal information to these systems can create } \\
\text { many unwanted problems }\end{array}$ & $3.77 \pm 1.58$ & \\
\hline & \multirow[t]{4}{*}{ Privacy Control } & $\begin{array}{l}\text { I believe I have control over those who have access to my } \\
\text { personal information collected by WLTR. }\end{array}$ & $4.34 \pm 1.50$ & \multirow[t]{4}{*}{$4.37 \pm 1.46$} \\
\hline & & $\begin{array}{l}\text { I think that I have control over that part of my personal } \\
\text { information released by these systems. }\end{array}$ & $4.28 \pm 1.47$ & \\
\hline & & $\begin{array}{l}\text { I believe I can control how my personal information is } \\
\text { handled by these systems. }\end{array}$ & $4.38 \pm 1.37$ & \\
\hline & & $\begin{array}{l}\text { I believe I can control the personal information I have } \\
\text { provided to these systems. }\end{array}$ & $4.49 \pm 1.51$ & \\
\hline & \multirow[t]{3}{*}{$\begin{array}{l}\text { Disposition to } \\
\text { Value Privacy }\end{array}$} & $\begin{array}{l}\text { Compared to others, I have a greater sensitivity to the ways in } \\
\text { which my online personal health information is used. }\end{array}$ & $5.67 \pm 1.52$ & \multirow[t]{3}{*}{$5.76 \pm 1.48$} \\
\hline & & For me, the most important thing is privacy in online systems. & $5.81 \pm 1.50$ & \\
\hline & & Compared to others, I am more worried about privacy risks. & $5.80 \pm 1.44$ & \\
\hline & \multirow{3}{*}{$\begin{array}{l}\text { Awareness to } \\
\text { Privacy }\end{array}$} & I am aware of privacy issues and practices in my community. & $4.91 \pm 1.43$ & \multirow[t]{3}{*}{$4.75 \pm 1.44$} \\
\hline & & $\begin{array}{l}\text { I follow the news and developments regarding privacy issues } \\
\text { violations. }\end{array}$ & $4.71 \pm 1.42$ & \\
\hline & & $\begin{array}{l}\text { I update my information about privacy issues and solutions } \\
\text { that companies and governments use to protect our privacy. }\end{array}$ & $4.62 \pm 1.48$ & \\
\hline & \multirow[t]{3}{*}{\begin{tabular}{|l} 
Social Norm \\
(NORM)
\end{tabular}} & $\begin{array}{l}\text { People, who affect my behavior, think that the privacy of } \\
\text { personal information is very important. }\end{array}$ & $5.58 \pm 0.94$ & \multirow[t]{3}{*}{$5.70 \pm 0.94$} \\
\hline & & My friends believe that I should be careful about my privacy. & $5.75 \pm 0.90$ & \\
\hline & & $\begin{array}{l}\text { The people, who are important to me, think that I should be } \\
\text { careful when revealing personal information online. }\end{array}$ & $5.76 \pm 0.99$ & \\
\hline & Disposition to & In general, people really care about the welfare of others & $4.91 \pm 1.45$ & $4.93 \pm 1.61$ \\
\hline
\end{tabular}




\begin{tabular}{|c|c|c|c|c|}
\hline \multirow[t]{8}{*}{ to Trust } & \multirow[t]{3}{*}{ Trust } & In general, most people keep their covenant. & $4.58 \pm 1.45$ & \\
\hline & & $\begin{array}{l}\text { I believe that most professional people do their job in the best } \\
\text { way. }\end{array}$ & $5.80 \pm 1.32$ & \\
\hline & & $\begin{array}{l}\text { I usually trust people until they give me some reason not to } \\
\text { trust them. }\end{array}$ & $4.43 \pm 1.82$ & \\
\hline & \multirow[t]{5}{*}{$\begin{array}{l}\text { Institution-Based } \\
\text { Trust }\end{array}$} & $\begin{array}{l}\text { I feel good about doing processes when I buy or do other } \\
\text { activities on the Internet. }\end{array}$ & $3.95 \pm 1.78$ & \multirow[t]{5}{*}{$3.72 \pm 1.69$} \\
\hline & & $\begin{array}{l}\text { I feel that most Internet service vendors are doing the best for } \\
\text { their customers. }\end{array}$ & $4.09 \pm 1.70$ & \\
\hline & & I easily trust Internet vendors in meeting their obligations. & $3.61 \pm 1.63$ & \\
\hline & & $\begin{array}{l}\text { In general, most Internet vendors are competent to serve their } \\
\text { customers. }\end{array}$ & $3.88 \pm 1.55$ & \\
\hline & & $\begin{array}{l}\text { The Internet is safe enough to make me feel comfortable with } \\
\text { using my personal business activities. }\end{array}$ & $3.08 \pm 1.65$ & \\
\hline \multirow{18}{*}{$\begin{array}{l}\text { The individuals or } \\
\text { organizations should be } \\
\text { able to use my personal } \\
\text { health information, }\end{array}$} & \multirow{9}{*}{$\begin{array}{l}\text { If I could be } \\
\text { identified: }\end{array}$} & Administrators (health care) & $5.22 \pm 1.96$ & \multirow[t]{9}{*}{$4.80 \pm 1.96$} \\
\hline & & Drug Companies & $5.02 \pm 1.91$ & \\
\hline & & Employers (if you were working) & $3.68 \pm 2.04$ & \\
\hline & & Government Insurers & $4.42 \pm 2.02$ & \\
\hline & & Insurance Companies & $4.41 \pm 2.01$ & \\
\hline & & Lawyers & $4.22 \pm 1.91$ & \\
\hline & & Medical Device Manufacturers & $4.74 \pm 1.93$ & \\
\hline & & Medical Doctors & $6.21 \pm 0.86$ & \\
\hline & & Medical Students & $5.22 \pm 1.65$ & \\
\hline & \multirow{9}{*}{$\begin{array}{l}\text { If I could not be } \\
\text { identified: }\end{array}$} & Administrators (health care) & $6.34 \pm 0.84$ & \multirow[t]{9}{*}{$6.16 \pm 1.14$} \\
\hline & & Drug Companies & $6.18 \pm 1.13$ & \\
\hline & & Employers (if you were working) & $5.94 \pm 1.38$ & \\
\hline & & Government Insurers & $6.01 \pm 1.29$ & \\
\hline & & Insurance Companies & $6.01 \pm 1.33$ & \\
\hline & & Lawyers & $6.02 \pm 1.28$ & \\
\hline & & Medical Device Manufacturers & $6.14 \pm 1.15$ & \\
\hline & & Medical Doctors & $6.57 \pm 0.60$ & \\
\hline & & Medical Students & $6.28 \pm 0.98$ & \\
\hline \multirow{8}{*}{$\begin{array}{l}\text { The use of my personal } \\
\text { health information } \\
\text { should be allowed, }\end{array}$} & \multirow{4}{*}{$\begin{array}{l}\text { If I could be } \\
\text { identified: }\end{array}$} & Education & $4.82 \pm 2.03$ & \multirow[t]{4}{*}{$5.15 \pm 1.89$} \\
\hline & & Health Care Administration & $5.75 \pm 1.60$ & \\
\hline & & Insurance Purposes & $5.30 \pm 1.71$ & \\
\hline & & Research & $4.71 \pm 2.03$ & \\
\hline & \multirow{4}{*}{$\begin{array}{l}\text { If I could not be } \\
\text { identified: }\end{array}$} & Education & $6.42 \pm 0.75$ & \multirow[t]{4}{*}{$6.45 \pm 0.73$} \\
\hline & & Health Care Administration & $6.52 \pm 0.67$ & \\
\hline & & Insurance Purposes & $6.42 \pm 0.75$ & \\
\hline & & Research & $6.41 \pm 0.77$ & \\
\hline
\end{tabular}

Table 2. Demographic characteristics of patients $(\mathrm{n}=81)$

\begin{tabular}{|l|l|l|l|l|}
\hline Variable & Mean \pm SD & $\mathrm{n}$ & $\%$ \\
\hline Age (year) & Male & $45.26 \pm 14.39$ & - & - \\
\hline \multirow{3}{*}{ Sex } & Female & - & 44 & 54.3 \\
\hline \multirow{4}{*}{ Education level } & Under diploma & - & 37 & 45.7 \\
\cline { 2 - 5 } & Diploma & - & 33 & 40.7 \\
\cline { 2 - 5 } & Associate & - & 40 & 49.4 \\
\cline { 2 - 5 } & Bachelor & - & 2 & 2.5 \\
\cline { 2 - 5 } & Master & - & 6 & 7.4 \\
\cline { 2 - 6 } & Doctor of Philosophy & - & 0 & 0 \\
\hline
\end{tabular}


Table 3. Comparison of Patients' views on privacy concerns in relation to patients' characteristics

\begin{tabular}{|l|l|l|l|}
\hline \multirow{2}{*}{ Variable } & \multicolumn{2}{l|}{ p-value* } \\
\cline { 2 - 4 } & Age & Level of education & Gender \\
\hline dissatisfied with giving information to websites & $\mathrm{NA}^{* *}$ & $0.041^{* * *}$ & NA \\
\hline the sensitivity to using online personal health information & NA & NA & $0.008^{* * * *}$ \\
\hline use the Internet to perform activities & $0.023^{* * * *}$ & NA & NA \\
\hline convenience of using web-based systems & 0.033 & NA & NA \\
\hline
\end{tabular}

$* \mathrm{p}$-value is significant when less than $0.05, * *$ Abbreviation: NA, No statistically significant correlation available. $* * *$ using Kruskal-Wallis Test, $* * * *$ using two-tailed Mann-Whitney U test, $* * * * *$ using Spearman's

Rank-Order Correlation test

\section{Discussion}

The present study aimed to develop an instrument to assess privacy challenges of a web-based liver transplantation registry (WLTR), and to determine the views of patients on the privacy of the implemented WLTR. The results revealed that the privacy issue in WLTR is very important for patients and they were concerned about the use of their information in this online registry system.

Privacy concerns of WLTR patients may affect their health outcomes. Previous studies have shown that privacy concerns have a negative effect on the patient's tendency to disclose health information online, which could endanger the health and well-being of the patient $(31,32)$. For instance, the Department of Health and Human Services of the United States estimates that nearly two million Americans who suffer from mental illnesses have never sought treatment because of their privacy concerns (33). Generally, the number of patients affected by privacy violations has increased from around half a million in 2008 to around 9 million in 2014 (34). This evidence brings forth the hypothesis that privacy concerns of patients on WLTR may negatively affect their health outcomes and examination of this hypothesis is recommended for future studies

In the present study, the results showed that no oral explanations or statements have been provided regarding the confidentiality of information and patients' privacy protection. McCabe et al. (2011) revealed registries should be managed in favor of participants while providing information for participants, medical care providers, and government agencies and they should be aware of the type of information that will be collected from a registry database or any other research database, as well as the type of study that will be implemented (35). Including this information in the informed consent of WLTR may motivate patients to participate in the program.

The findings revealed that some of the demographic information of patients is associated with their privacy concerns. These findings are in line with the findings of a King et al. study which concluded that age, place of birth, and employment status are related to privacy concerns (14). The results also showed that, in comparison to men, women are more sensitive and worried about protecting their online privacy and using this information. Previous studies have reported that women are more concerned about the privacy of their online information compared to men $(8,36-38)$, and men are more willing to give their information to websites (39), which highlight that our study is in line with previous findings. Although, several studies have shown that young people and those with a higher level of education spend a lot of time seeking online health care information (40), the study revealed that higher educated patients felt more dissatisfied with giving information to websites. It seems the familiarity and awareness of these individuals regarding the security risks and challenges of web-based systems may be the cause of this concern.

The study, similar to other studies showed that anonymization, deleting or never using the identifiable elements such as the name or date of birth of patients' information, may greatly reduce their concerns about privacy $(14,41)$. In contrast to a Cannoy and Salam qualitative study (43), the present quantitative study similar to other studies (42) demonstrated that the majority of patients are comfortable with sharing information among physicians. This controversy might be caused by different study designs. The study suggests performing a qualitative research on the subject in the study area and comparing its results with these findings. Moreover, the findings of this study in contrast to a study by Ancker et al. (44) showed that patients were worried about providing their information to insurance companies. To address these concerns, patients should be assured that their information would not be used without permission. Also, Information disclosure policies should be clearly identified and the anonymization of information should be done before disclosing. 
Unreliability about the confidentiality of information may negatively affect participation in research studies (45). The study revealed that patients are worried about the possibility of unauthorized access to information and the use of it. Obtaining permission before using patients' health information can positively affect their participation in researches.

Most study participants considered the role of WLTR to be useful in improving quality of care. Generally, studies have shown that paying attention to the concerns of individuals regarding privacy is effective in the adoption and success of implementing health information systems (46). In regard to trust, the majority of participants in this study believed that most professional people do their job in the best way, although privacy concerns can be the major cause of lack of trust between customers and service providers (47). We think trust of WLTR and care team can affect the patient's medication adherence and continuity of care. However, examining this hypothesis needs to be included in further studies.

Our study had some limitations. First, in spite of including all registered patients in the study, participants were still low in number. Second, using a quantitative method meant that the study could not assess cultural factors, which potentially could affect people's concerns about privacy. The study suggests assessing this subject by using a qualitative method for future studies. In addition, the lack of a systematic literature review in designing the instrument, limits it to be an evidence-based instrument and using a qualitative method to design the final instrument by Delphi technique may limit the generalization of the results.

\section{Conclusions}

In summary, the findings of this study showed that, despite the fact that patients consider the role of the WLTR to be effective in the process of care, it is important for them to protect privacy in these systems, and patients are very worried about the use of their information in the registry programs. The practical significance of the findings is that it guides developers to develop policies in accordance with the objectives of the registries and users' characteristics and concerns. It is suggested that regular training programs be developed for awareness of health care personnel and users involved with registry systems regarding patient privacy and confidentiality. Further research on the views of healthcare providers on privacy of the WLTR could be useful.

\section{Acknowledgments:}

The authors would like to thank the Research Deputy of Mashhad University of Medical Sciences for its financial and administrative support in this study (Grant Number: 951256).

\section{Conflict of Interest:}

There is no conflict of interest to be declared.

\section{Authors' contributions:}

All authors contributed to this project and article equally. All authors read and approved the final manuscript.

\section{References:}

1) Berg CL. Liver Transplantation in 2016: An Update. N C Med J. 2016; 77(3): 194-7. doi: 10.18043/ncm.77.3.194. PMID: 27154889.

2) Raeisi Shahraki H, Pourahmad S, Ayatollahi SMT. Identifying the Prognosis Factors in Death after Liver Transplantation via Adaptive LASSO in Iran. J Environ Public Health. 2016; 2016: 6. doi: 10.1155/2016/7620157. PMID: 27648080.

3) Mahdavi-Mazdeh M, Rouchi AH, Rajolani H, Norouzi S, Aghighi M, Ahrabi S. Transplantation Registry in Iran. Transplantation Proceedings. 2008; 40(1): 126-8. doi: 10.1016/j.transproceed.2007.11.010.

4) De Villa V, Lo CM. Liver transplantation for hepatocellular carcinoma in Asia. Oncologist. 2007; 12(11): 1321-31. doi: 10.1634/theoncologist.12-11-1321. PMID: 18055852.

5) Kazemeyni SM, Aghighi M. Organ Procurement from Deceased Donors and its Impact on Organ Transplantation in Iran during the First Ten Years of Cadaveric Transplantation. Int J Organ Transplant Med. 2012; 3(3): 125-9. PMID: 25013636, PMCID: PMC4089290.

6) Aliakbarian M. Abstracts from International Congress of Transplantation and Implantation, November 2015, Mashhad, Iran. IJOTM. 2016; 7(2): 137-8.

7) Abdelhak M, Grostick S, Hanken MA. Health Information-E-Book: Management of a Strategic Resource: Elsevier Health Sciences; 2014. 
8) Terry AL, Chesworth BM, Stolee P, Bourne RB, Speechley M. Joint replacement recipients' post-surgery views about health information privacy and registry participation. Health policy. 2008; 85(3): 293-304. doi: 10.1016/j.healthpol.2007.08.002. PMID: 17904684.

9) Sarbaz M, Kimiafar K, Sheikhtaheri A, Taherzadeh Z, Eslami S. Nurses' Information Seeking Behavior for Clinical Practice: A Case Study in a Developing Country. Stud Health Technol Inform. 2016; 225: 23-7. PMID: 27332155.

10) Gliklich RE, Dreyer NA, Leavy MB. Registries for evaluating patient outcomes: a user's guide: Government Printing Office; 2014.

11) Li F, Li M, Guan P, Ma S, Cui L. Mapping publication trends and identifying hot spots of research on Internet health information seeking behavior: a quantitative and co-word biclustering analysis. J Med Internet Res. 2015; 17(3): e81. doi: 10.2196/jmir.3326. PMID: 25830358.

12) Schweiger S, Oeberst A, Cress U. Confirmation bias in web-based search: a randomized online study on the effects of expert information and social tags on information search and evaluation. J Med Internet Res. 2014; 16(3): e94. doi: 10.2196/jmir.3044. PMID: 24670677.

13) Nelson SB. Privacy and medical information on the Internet. Respir Care. 2006; 51(2): 183-7. PMID: 16441962 .

14) King T, Brankovic L, Gillard P. Perspectives of Australian adults about protecting the privacy of their health information in statistical databases. Int $\mathrm{J}$ Med Inform. 2012; 81(4): 279-89. doi: 10.1016/j.ijmedinf.2012.01.005. PMID: 22306206.

15) Abel WM, Efird JT. The Association between Trust in Health Care Providers and Medication Adherence among Black Women with Hypertension. Front Public Health. 2013; 1: 66. doi: 10.3389/fpubh.2013.00066. PMID: 24350234.

16) Rolfe A, Cash-Gibson L, Car J, Sheikh A, McKinstry B. Interventions for improving patients' trust in doctors and groups of doctors. Cochrane Database Syst Rev. 2014(3): CD004134. doi: 10.1002/14651858.CD004134.pub3. PMID: 24590693.

17) Aliakbarian M, Tohidinezhad F, Eslami S, Akhavan-Rezayat K. Liver transplantation for hepatic alveolar echinococcosis: literature review and three new cases. Infect Dis (Lond). 2018; 50(6): 452-9. doi: 10.1080/23744235.2018.1428823. PMID: 29363377.

18) Goshayeshi L, Ghaffarzadegan K, Khooei A, Esmaeilzadeh A, Rahmani Khorram M, Mosannen Mozaffari $\mathrm{H}$, et al. Prevalence and clinicopathological characteristics of mismatch repair-deficient colorectal carcinoma in early onset cases as compared with late-onset cases: a retrospective cross-sectional study in Northeastern Iran. BMJ Open. 2018; 8(8): e023102. doi: 10.1136/bmjopen-2018-023102. PMID: 30166308.

19) Goshayeshi L, Khooiee A, Ghaffarzadegan K, Rahmani Khorram M, Bishehsari F, Hoseini B, et al. Screening for Lynch Syndrome in Cases with Colorectal Carcinoma from Mashhad. Arch Iran Med. 2017; 20(6): 332-7. doi: 0172006/AIM.003. PMID: 28646840.

20) Tohidinezhad F, Eslami S, Abu-Hanna A, Aliakbarian M. Model for End-Stage Liver Disease and Seven Derivations to Prioritize Liver Transplant Candidates: Which Is the Winner? Exp Clin Transplant. 2018. doi: 10.6002/ect.2017.0149. PMID: 29457445.

21) Rhonda J, Richards. A study of the intent to fully utilize electronic personal health records in the context of privacy and trust. Ann Arbor: University of North Texas; 2012.

22) Amanda L. Terry. The effect of privacy attitudes on willingness to participate in registries: Views of joint replacement patients. Ann Arbor: The University of Western Ontario (Canada); 2006.

23) Eloranta K, Auvinen A. Population attitudes towards research use of health care registries: a populationbased survey in Finland. BMC Med Ethics. 2015; 16(1): 48. doi: 10.1186/s12910-015-0040-x. PMID: 26183438.

24) Saghar Behrooz. Trust-Based Framework for Information Sharing in Health Care. Ann Arbor: University of Ontario Institute of Technology (Canada); 2016.

25) Myhre SL, Kaye J, Bygrave LA, Aanestad M, Ghanem B, Mechael P, et al. e Registries: governance for electronic maternal and child health registries. BMC Pregnancy Childbirth. 2016; 16(1): 279. doi: 10.1186/s12884-016-1063-0. PMID: 27663979.

26) Michelle Erin Gordon. A Framework for the Protection of Privacy in an Electronic Health Environment. Ann Arbor: University of Toronto (Canada); 2010.

27) Laurie A. Friedman. Patient experience of privacy while participating in group healthcare: A phenomenographic description. Ann Arbor: Boston College; 2015. 
28) Aljurf M, Rizzo JD, Mohty M, Hussain F, Madrigal A, Pasquini MC, et al. Challenges and opportunities for HSCT outcome registries: perspective from international HSCT registries experts. Bone Marrow Transplant. 2014; 49(8): 1016-21. doi: 10.1038/bmt.2014.78. PMID: 24777183.

29) Rachida Fachtal Parks. A study of organizational responses to information privacy threats in the healthcare context. Ann Arbor: The Pennsylvania State University; 2012.

30) Hsu CC, Sandford BA. The Delphi technique: making sense of consensus. Practical assessment, research \& evaluation. 2007; 12(10): 1-8.

31) Bansal G, Zahedi FM, Gefen D. The impact of personal dispositions on information sensitivity, privacy concern and trust in disclosing health information online. Decision Support Systems. 2010; 49(2): 138-50. doi: 10.1016/j.dss.2010.01.010.

32) Anderson CL, Agarwal R. The Digitization of Healthcare: Boundary Risks, Emotion, and Consumer Willingness to Disclose Personal Health Information. Inf Syst Res. 2011; 22(3): 469-90. doi: 10.1287/isre.1100.0335.

33) Yüksel B, Küpçü A, Özkasap Ö. Research issues for privacy and security of electronic health services. Future Gener Comput Syst. 2017; 68: 1-13. doi: 10.1016/j.future.2016.08.011.

34) Lapke M, Garcia C, Henderson D. The disconnect between healthcare provider tasks and privacy requirements. Health Policy Technol. 2017; 6(1): 12-9. doi: 10.1016/j.hlpt.2016.08.004.

35) McCabe LL, McCabe ERB. Down syndrome: Issues to consider in a national registry, research database and biobank. Mol Genet Metab. 2011; 104(1-2): 10-2. doi: 10.1016/j.ymgme.2011.03.018. PMID: 21501965.

36) Lankton NK, McKnight DH, Tripp JF. Facebook privacy management strategies: A cluster analysis of user privacy behaviors. Comput Human Behav. 2017; 76: 149-63. doi: 10.1016/j.chb.2017.07.015.

37) Rowan M, Dehlinger J. Observed Gender Differences in Privacy Concerns and Behaviors of Mobile Device End Users. Procedia Comput Sci. 2014; 37: 340-7. doi: 10.1016/j.procs.2014.08.050.

38) Mohamed N, Ahmad IH. Information privacy concerns, antecedents and privacy measure use in social networking sites: Evidence from Malaysia. Comput Human Behav. 2012; 28(6): 2366-75. doi: 10.1016/j.chb.2012.07.008.

39) Youn S. Determinants of Online Privacy Concern and Its Influence on Privacy Protection Behaviors Among Young Adolescents. J Consum Aff. 2009; 43(3): 389-418. doi: 10.1111/j.1745-6606.2009.01146.x.

40) Cotten SR, Gupta SS. Characteristics of online and offline health information seekers and factors that discriminate between them. Soc Sci Med. 2004; 59(9): 1795-806. doi: 10.1016/j.socscimed.2004.02.020. PMID: 15312915.

41) Gal TS, Tucker TC, Gangopadhyay A, Chen Z. A data recipient centered de-identification method to retain statistical attributes. J Biomed Inform. 2014; 50: 32-45. doi: 10.1016/j.jbi.2014.01.001. PMID: 24412834.

42) Kimiafar K, Sarbaz M, Shahid Sales S, Esmaeili M, Javame Ghazvini Z. Breast cancer patients' information needs and information-seeking behavior in a developing country. Breast. 2016; 28: 156-60. doi: 10.1016/j.breast.2016.05.011. PMID: 27318171.

43) Cannoy SD, Salam AF. A framework for health care information assurance policy and compliance. Commun ACM. 2010; 53(3): 126-31. doi: 10.1145/1666420.1666453.

44) Ancker JS, Silver M, Miller MC, Kaushal R. Consumer experience with and attitudes toward health information technology: a nationwide survey. J Am Med Inform Assoc. 2013; 20(1): 152-6. doi: 10.1136/amiajnl-2012-001062. PMID: 22847306.

45) Mascalzoni D, Paradiso A, Hansson M. Rare disease research: Breaking the privacy barrier. Appl Transl Genom. 2014; 3(2): 23-9. doi: 10.1016/j.atg.2014.04.003. PMID: 27275410.

46) Sadoughi F, Kimiafar K, Ahmadi M, Shakeri MT. Determining of factors influencing the success and failure of hospital information system and their evaluation methods: a systematic review. Iran Red Crescent Med J. 2013; 15(12): e11716. doi: 10.5812/ircmj.11716. PMID: 24693386.

47) Midha V. Impact of consumer empowerment on online trust: An examination across genders. Decision Support Systems. 2012; 54(1): 198-205. doi: 10.1016/j.dss.2012.05.005. 